\title{
Researches on the Spectral Transmittance of Zinc Oxide ZnO Semiconductor Layers
}

\author{
P. StruK*, T. Pustelny And Z. Opilski \\ Department of Optoelectronics, Silesian University of Technology, Akademicka 2a, Gliwice, Poland

\begin{abstract}
The paper deals with investigations concerning a wide-band gap material, viz. zinc oxide ZnO. Special attention has been devoted to the determination of the spectral transmission of zinc oxide layers deposited on quartz substrates. These investigations have made it possible to determine the optical spectral range in which this material is transparent as well as the edges of absorption. The presented investigations are valuable particularly concerning the application of zinc oxide in optoelectronic and photonic structures as well as in systems of waveguides and sensor layers of integrated optics.
\end{abstract}

PACS numbers: $42.25 . \mathrm{Hz}, 42.25 .-\mathrm{p}, 42.82 . \mathrm{Et}, 68.35 . \mathrm{Ct}$

\section{Introduction}

Semiconductor materials with a wide energy band gap offer very attractive possibilities of application, among others in electric and optoelectronic structures. Among the wide-band gap materials zinc oxide is particularly interesting, being very promising when applied in electronic and optoelectronic devices within the range ultraviolet and blue light, and in photonic waveguide and sensor structures [1]. ZnO possesses optical attractiveness thanks among others, to the fact that it is characterized by a wide energy band gap on the level $E_{\mathrm{g}} \approx 3.3 \mathrm{eV}[1]$. It is also characterized by its high value of the refractive index amounting to $n \approx 2[1,2]$. Moreover, zinc oxide is a transparent semiconductor in the visible range of the spectrum $[3,4]$. Investigations on the application of zinc oxide in those applications mentioned above have been carried out already for many years, but only due to the progress of the technology of producing structures basing on this semiconductor the interest in $\mathrm{ZnO}$ has grown considerably. Layers of zinc oxide can be obtained in various ways, among others by RF magnetron sputtering (RF MBS), molecular beam epitaxy (MBE), pulsed laser deposition (PLD), chemical vapor deposition (CVD) and electron beam evaporation (E-beam) [1-4]. Such a wide range of methods of applying zinc oxide permits to get layers with various properties and various qualities of the surface structure, as well as electronic and optical properties. From the viewpoint of applying $\mathrm{ZnO}$ in optoelectronic structures, including photonic and waveguide structures, important are its optical parameters. The presented paper concentrates on the determination of the spectral transmission of light through the

\footnotetext{
* corresponding author; e-mail: Przemyslaw.Struk@polsl.pl
}

$\mathrm{ZnO}$ layers. The investigations permitted to determine in which range of the spectrum the materials elaborated by us are transparent and for which wavelengths the edge of absorption does occur.

The behavior of the electromagnetic wave at the boundaries of materials with various refractive indices has been illustrated schematically in Fig. 1a. Some part of the energy of the incident wave is reflected at the boundaries, characterized by different refractive indices $n_{\mathrm{c}}$ and $n_{\mathrm{w}}$. Some part of the optical energy is transmitted through the investigated structure. The optical signal transmitted through the structure was recorded by the spectrometer.
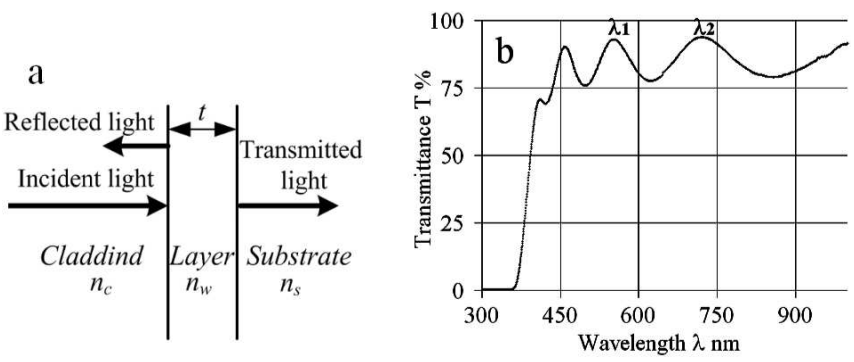

Fig. 1. (a) Transmission and reflection of light through the thin layer structure; (b) transmission as a function of the wavelength.

The performed spectrometric investigations permit also to determine the depth of the layer of zinc oxide (at a known value of its refractive index) deposited on the quartz substrate. In order to determine the thickness of the $\mathrm{ZnO}$ layer we must determine the wavelengths, at which the maximum and minimum values of transmissions of the optical signal do occur (Fig. 1b). (As has already been said, we must know the relation of the re- 
fractive index as a function of the light wavelength.) Relevant investigations have been dealt with in [2]. Thus, the thickness of the investigated layers may be expressed by Eq. (1) $[4,5]$ :

$$
t=\frac{\lambda_{1} \lambda_{2} M}{2\left[n_{\mathrm{w}}\left(\lambda_{1}\right) \lambda_{2}-n_{\mathrm{w}}\left(\lambda_{2}\right) \lambda_{1}\right]},
$$

where $\lambda_{1}, \lambda_{2}$ - wavelengths, corresponding to the maximum or minimum transmission, $n_{\mathrm{w}}\left(\lambda_{1}\right), n_{\mathrm{w}}\left(\lambda_{2}\right)-$ refractive indices of light in the investigated layers, $M$ amount of oscillation between two considered maximum values $(M=1$ when the maximum values of transmission are near to such other).

\section{Experimental}

The aim of the investigations was to determine the optical properties of the zinc oxide layers produced at the Institute of Electron Technology in Warsaw. These investigations concentrated on the determination of the spectral transmission of the zinc oxide layers deposited on a quartz substrate concerning the technology of their production and soaking of the layers following the process of their deposition. The optical spectral properties of the zinc oxide layers were tested spectrometrically. The test stand consisted of the Spectrometer HR 2000+ES, produced by the Ocean Optics Corp., the light source Ocean Optics DT-mini-2-Gs and a PC computer for the data acquisition. The scheme of the test stand can be seen in Fig. 2.

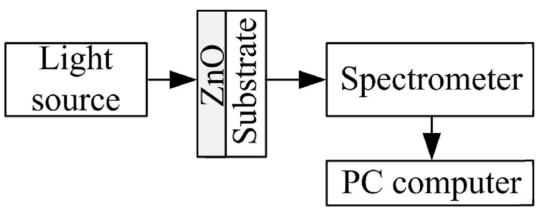

Fig. 2. Scheme of the measuring test stand.

The transmission of light through the tested zinc oxide layers was measured by means of the spectrometer as follows. First, the dark intensity signal $D_{\lambda}$ was measured, then the signal with the $\mathrm{ZnO}$ layer deposited on the quartz substrate $S_{\lambda}$ - sample intensity, and also the reference signal without the quartz substrate and without the $\mathrm{ZnO}$ layer $-R_{\lambda}$ reference intensity. Finally, the transmission of light in the $\mathrm{ZnO}$ layer was determined by means of Eq. (2) [6, 7]:

$$
T=\frac{S_{\lambda}-D_{\lambda}}{R_{\lambda}-D_{\lambda}} \cdot 100 \% .
$$

The investigated zinc oxide layers were deposited on quartz substrates applying the method of reactive magnetron cathode sputtering. The process of deposition was carried out in RF mode in atmosphere of $30 \% \mathrm{O}_{2}$ and $70 \% \mathrm{Ar}$, using a ceramic target, the current of the cathode amounting to $I_{\mathrm{c}}=140 \mathrm{~mA}$, the total pressure to $p_{\mathrm{Ar}+\mathrm{O} 2}=1 \times 10^{-2}$ mbar and the partial pressure of oxygen to $p_{\mathrm{O} 2}=3 \times 10^{-3}$ mbar. The rate of deposition of zinc oxide on the quartz substrate was $V_{\mathrm{d}}=0.4 \mathrm{~nm} / \mathrm{s}$. The substrates are not additionally preheated during the deposition. Some of the produced structures were annealed applying the method of rapid thermal annealing (RTA) in order to remove mechanical stresses and to arrange the crystalline structure [8].

\section{Results}

The process of annealing the respective $\mathrm{ZnO}$ layers was realized as follows:

- $\mathrm{ZnO}_{-} 1$ annealing for $10 \mathrm{~min}$ successively at $400{ }^{\circ} \mathrm{C}$ in $\mathrm{N}_{2}$ and at $500{ }^{\circ} \mathrm{C}$ in $\mathrm{O}_{2}$ also for $10 \mathrm{~min}$;

- $\mathrm{ZnO} \_2$ annealing for $10 \mathrm{~min}$ successively: at $400^{\circ} \mathrm{C}$ in $\mathrm{N}_{2}$ and at $500{ }^{\circ} \mathrm{C}$ in $\mathrm{O}_{2}$ and $600{ }^{\circ} \mathrm{C}$ in $\mathrm{O}_{2}$;

- $\mathrm{ZnO}_{3} 3$ was not subjected to annealing after its deposition.

The results of these investigations of the spectral transmission have been gathered in Fig. 3 .

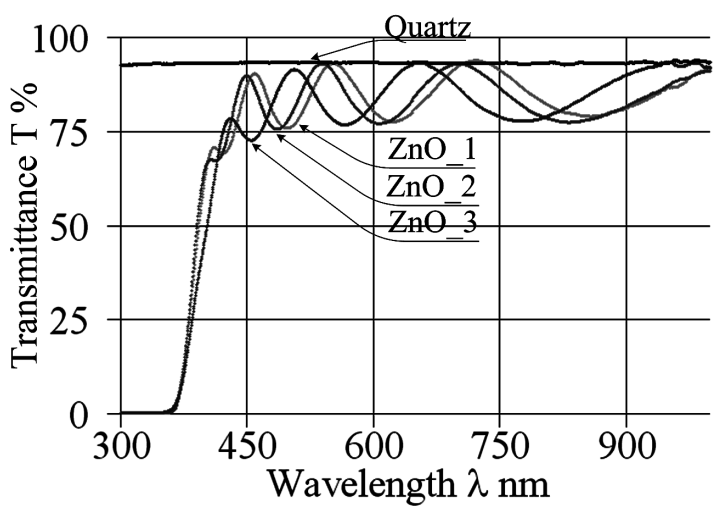

Fig. 3. Characteristics of the spectral transmission of $\mathrm{ZnO}$ layers.

The analysis of the spectral transmission of light through zinc oxide layers has shown that this material is transparent in the visible range in the spectral range of the wavelengths $\lambda$ from about $400 \mathrm{~nm}$. (The high spectrum range of the used spectrometer was restricted to $1000 \mathrm{~nm}$.)

The spectrometric measurements also indicated the influence of the process of deposition and annealing of $\mathrm{ZnO}$ layers on the edge of light absorption. Layers annealed in compliance with the technology RTA display an absorption edge at shorter wavelengths than the layers which were not subjected to soaking (Fig. 3). The transmission of light as a function of the wavelength was also measured for the quartz substrate as a reference signal. (Obviously, in this case no absorption edge was detected.) Basing on the spectral characteristics and on Eq. (1), the thicknesses $d$ of the zinc oxide layers were determined. For this purpose, the wavelengths of two adjacent maximum values of the transmission $\lambda_{1}$ and $\lambda_{2}$ were measured. The values of the refractive index at the respective wavelengths $n\left(\lambda_{1}\right)$ and $n\left(\lambda_{2}\right)$ were determined basing on 
Eq. (1). The quoted parameters, as well as the determined thicknesses of the $\mathrm{ZnO}$ layers have been gathered in Table.

Parameters of tested $\mathrm{ZnO}$ layers

TABLE

\begin{tabular}{c|c|c|c|c|c}
\hline \hline \multirow{2}{*}{ Layer } & \multicolumn{2}{|c|}{ Wavelength [nm] } & \multicolumn{2}{c|}{ Refractive index } & Thickness \\
\cline { 2 - 5 } & $\lambda_{1}[\mathrm{~nm}]$ & $\lambda_{2}[\mathrm{~nm}]$ & $n_{\mathrm{w}}\left(\lambda_{1}\right)$ & $n_{\mathrm{w}}\left(\lambda_{2}\right)$ & $t[\mathrm{~nm}]$ \\
\hline $\mathrm{ZnO}+1$ & 555.85 & 727.13 & 2.00 & 1.96 & 554 \\
$\mathrm{ZnO}_{2} 2$ & 541.43 & 705.70 & 2.02 & 1.96 & 524 \\
$\mathrm{ZnO}_{3}$ & 508.95 & 659.21 & 2.04 & 1.97 & 490
\end{tabular}

\section{Summary}

The applied spectroscopic testing method provides valuable optical information concerning the thin waveguide layers. The performed investigations permitted to determine for the $\mathrm{ZnO}$ layer such parameters as their spectrum of transmission and the edge of absorption. The presented results indicate that zinc oxide layers are optically transparent in the wide wavelength ranges from about $400 \mathrm{~nm}$. Moreover, the performed tests have made it possible to determine the edges of light absorption in very thin $\mathrm{ZnO}$ layers. Besides, the spectroscopic method permits in the same process to determine the thicknesses of the layers and hence their modal characteristics. The obtained results were used for projecting and elaborating photonic structures with the Bragg gratings performed in $\mathrm{ZnO}$ layers.

\section{Acknowledgments}

The work was sponsored by the State Committee for Scientific Research within the Structural Program WND-POIG.01.03.01-00-159/08-00.

\section{References}

[1] Ü. Özgür, Ya.I. Alivov, C. Liu, A. Teke, M.A. Reshchikov, S. Dođan, V. Avrutin, S.-J. Cho, H. Morkoc, J. Appl. Phys. 98, 093520 (2005).

[2] P. Struk, T. Pustelny, K. Gut, K. Gołaszewska, E. Kaminska, M. Ekielski, I. Pasternak, E. Łusakowska, A. Piotrowska, Acta Phys. Pol. A 116, 414 (2009).

[3] K. Gołaszewska, E. Kaminska, T. Pustelny, P. Struk, T. Piotrowski, A. Piotrowska, M. Ekielski, R. Kruszka, M. Wzorek, M. Borysiewicz, I. Pasternak, K. Gut, Acta Phys. Pol. A 114, 221 (2008).

[4] R.G. Heideman, P.V. Lambeck, J. Gardeniers, Opt. Mater. 64, 741 (2005).

[5] J.C. Manifacier, J. Gasiot, J.P. Fillard, J. Phys. E, Sci. Instrum. 9, 156 (2003).

[6] A. Rogalski, Acta Phys. Pol. A 116, 389 (2009).

[7] SpectraSuite ${ }^{\circledR}$, Spectrometer Operating Software "Installation and Operation Manual" Document Number 000-20000-300-02-0810 Ocean Optics.

[8] B. Pustelny, T. Pustelny, Acta Phys. Pol. A 114, 383 (2009). 